Article type : Primary Research Articles

,

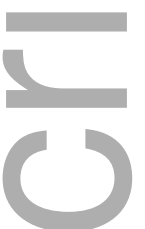

\title{
Australian wheat production expected to decrease by the late 21st century
}

Running head: Climate change impacts on Australian wheat

Authors: Bin Wang ${ }^{1 *}$, De Li Liu ${ }^{1,2}$, Garry J O'Leary ${ }^{3}$, Senthold Asseng ${ }^{4}$, Ian Macadam ${ }^{2,5}$, Rebecca Lines-Kelly ${ }^{6}$, Xihua Yang ${ }^{7}$, Anthony Clark ${ }^{8}$, Jason Crean ${ }^{8}$, Timothy Sides ${ }^{1}$, Hongtao Xing ${ }^{1,9}$, Chunrong $\mathrm{Mi}^{10}$ and Qiang $\mathrm{Yu}^{9,11,12}$

Affiliations: ${ }^{1}$ NSW Department of Primary Industries, Wagga Wagga Agricultural Institute, NSW 2650, Australia

${ }^{2}$ Climate Change Research Centre and ARC Centre of Excellence for Climate System Science, University of New South Wales, Sydney, NSW 2052, Australia

${ }^{3}$ Agriculture Victoria Research, Department of Economic Development, Jobs, Transport and Resources, 110 Natimuk Road, Horsham, Victoria, 3400 Australia

${ }^{4}$ Agricultural \& Biological Engineering Department, University of Florida, 221 Frazier Rogers Hall, P.O. Box 110570, Gainesville, FL 32611-0570, USA

${ }^{5}$ Met Office, FitzRoy Road, Exeter, EX1 3PB, UK

${ }^{6} \mathrm{NSW}$ Department of Primary Industries, Bruxner Highway, Wollongbar, NSW 2477, Australia

${ }^{7}$ New South Wales Office of Environment and Heritage, Parramatta, NSW 2150, Australia This is the author manuscript accepted for publication and has undergone full peer review but has not been through the copyediting, typesetting, pagination and proofreading process, which may lead to differences between this version and the Version of Record. Please cite this article as doi: $10.1111 /$ gcb.14034

This article is protected by copyright. All rights reserved 
${ }^{8}$ NSW Department of Primary Industries, Orange Agricultural Institute, NSW 2800, Australia

${ }^{9}$ School of Life Sciences, Faculty of Science, University of Technology Sydney, PO Box 123, Broadway, NSW 2007, Australia

${ }^{10}$ Key Laboratory of Water Cycle and Related Land Surface Processes, Institute of Geographic Sciences and Natural Resources Research, University of Chinese Academy of Sciences, Beijing, China

${ }^{11}$ State Key Laboratory of Soil Erosion and Dryland Farming on the Loess Plateau, Northwest A\&F University, Yangling 712100, Shaanxi, China

${ }^{12}$ College of Resources and Environment, University of Chinese Academy of Science, Beijing 100049, China

*Correspondence: Bin Wang, email: bin.a.wang@dpi.nsw.gov.au, T: +61 0269381600

Keywords: climate change; wheat yield; APSIM model; species distribution model; climate suitability; adaptation options.

Paper type: Primary research articles
Abstract
Climate change threatens global wheat production and food security, including the wheat industry in Australia. Many studies have examined the impacts of changes in local climate on wheat yield per hectare, but there has been no assessment of changes in land area available for production due to changing climate. It is also unclear how total wheat production would change under future climate when autonomous adaptation options are adopted. We applied species distribution models to investigate future changes in areas climatically suitable for growing wheat in Australia. A crop model was used to assess wheat yield per hectare in these areas. Our results show that there is an overall tendency for a decrease in the areas suitable for growing wheat and a decline in the yield of the northeast Australian wheat belt. This results in reduced national wheat production; though future climate change may benefit South Australia and Victoria. These projected outcomes infer that similar wheat growing regions of the globe might also experience decreases in wheat production. Some cropping adaptation measures increase wheat yield per hectare and provide significant mitigation of the negative 
effects of climate change on national wheat production by 2041-2060. However, any positive effects will be insufficient to prevent a likely decline in production under a high $\mathrm{CO}_{2}$ emission scenario by 2081-2100 due to increasing losses in suitable wheat growing areas. Therefore, additional adaptation strategies along with investment in wheat production are needed to maintain Australian agricultural production and enhance global food security. This scenario analysis provides a foundation towards understanding changes in Australia's wheat cropping systems, which will assist in developing adaptation strategies to mitigate climate change impacts on global wheat production.

\section{Introduction}

Global demand for agricultural products has been increased due to a growing human population, rising incomes, and changing patterns of food preferences and consumption (Grundy et al., 2016, Keating et al., 2014, Wheeler \& Von Braun, 2013). However, global climate change has significantly affected crop growth and development, altered crop cultivation patterns and potentially suitable planting areas, and has even resulted in considerable reductions in the production of major crops (e.g., wheat, rice and maize) (Balkovič et al., 2014, Liu et al., 2013b). Therefore, climate change poses a great threat to global food production and security (Wheeler \& Von Braun, 2013). However, there is a high uncertainty in future climate impacts in different regions of the globe (IPCC, 2013). These uncertainties, together with the rising food demand and mounting production challenges, make it urgent to promptly re-evaluate global agricultural capacity under future climate conditions.

Australia is a significant contributor in the world food market (FAOSTAT, 2014). During the past few decades, Australian agricultural productivity has increased despite a drying and warmer climate (Godden et al., 1998), largely as a result of improved crop cultivars, and crop management including fertilizers and water-conservation. About $65 \%$ of Australia's agricultural production is exported (Grundy et al., 2016). As one of the top five wheat exporting countries in the world, Australia accounts for $11 \%$ of global wheat trades during 2015 (Workman, 2017), its exports can compensate for wheat production fluctuations in other regions of the world and can potentially affect global wheat availability and global food security (Qureshi et al., 2013).

The climate of Australia is changing with temperature increasing by approximately $0.8^{\circ} \mathrm{C}$ since 1960 with more heatwaves, fewer frosts and an increase in the intensity of 
droughts (Cleugh et al., 2011). Recent climate projections for Australia show annual mean temperature increasing by approximately $1.4-2.7{ }^{\circ} \mathrm{C}$ for RCP4.5 and $2.8-5.1{ }^{\circ} \mathrm{C}$ for RCP8.5 by 2080-2099, with a possible decrease in spring and winter rainfall (CSIRO \& BoM, 2015). The combined effects of changing and uneven distribution of seasonal rainfall, and increasing temperatures could exacerbate the Australian wheat industry's current vulnerabilities and pose a challenge for export markets (Lawrence et al., 2013). For example, Australia's wheat is almost entirely grown under rainfed conditions and previous assessments of climate change impacts have demonstrated that a substantial decrease in productivity can be attributed to reductions in growing season rainfall (Anwar et al., 2015, Ludwig \& Asseng, 2006). However, increasing atmospheric carbon dioxide $\left(\mathrm{CO}_{2}\right)$ concentrations could enhance photosynthetic production and water use efficiency in crops, especially if nutrients are not limiting crop growth (Fitzgerald et al., 2016, Urban et al., 2015). For example, some previous crop modelling studies show that negative effects of increased temperatures on wheat yield are partially offset by the positive effects of higher $\mathrm{CO}_{2}$ concentrations (Fitzgerald et al., 2016, Ludwig \& Asseng, 2006, O'Leary et al., 2015, Wang et al., 2017c). Comprehensive assessment of the impacts of climate change on Australia's wheat industry requires the consideration of both climatic effects and the effects of $\mathrm{CO}_{2}$ increases, and the interactions between them.

The distribution of crops across the landscape depends on local climatic conditions (e.g. temperature and rainfall) as well as soil properties, terrain and competing land use (e.g. urban areas). Climate is an important factor in determining crop planting area and climate change may affect the spatial distribution of crops. It has been shown that in higher latitudes, higher temperatures could result in crop growing regions expanding as the growing season lengthens and crop yields rise (Ramirez-Cabral et al., 2016, Schmidhuber \& Tubiello, 2007). In China, for example, the northern limits of cropping systems have shifted north with global warming and contributed an additional $2.2 \%$ to national production of major crops (Yang et $a l ., 2015)$. In the Southern Hemisphere, future climatic conditions are less favourable for crop cultivation due to heat and lack of water (Ramirez-Cabral et al., 2016). Surprisingly, despite the importance of Australia's wheat to world trade and potential impacts from climate change, there is limited understanding of how the climate suitability for wheat may change across Australia's wheat belt (O'Leary et al., 2011). However, species distribution models (SDMs) (Elith \& Leathwick, 2009), which represent the association between species' occurrence and environmental, climatic and geographical predictors, can be applied to address this problem 
(Evangelista et al., 2013, Keenan et al., 2011, Liu et al., 2013a). For example, Bunn et al. (2015) have used SDMs to project coffee production on a global level and found that climate change will reduce the global area suitable for coffee by about $50 \%$ across emission scenarios. These statistical models have shown that aspects of rainfall and temperature are important predictors for many ecological processes and are being increasingly employed for projecting impacts of climate change (Evangelista et al., 2013, Shabani et al., 2016). For example, water stress is the main factor limiting the geographic distribution of common bean at a global scale (Ramirez-Cabral et al., 2016).

Assessments of climatic suitability of different regions for crop growth under climate change could inform local and global initiatives to develop adaptive strategies that can minimize negative impacts and address food security (He \& Zhou, 2016, Ramirez-Cabral et al., 2016). Numerous studies have already shown a net increase in wheat productivity with climate change and suitable adaptation options implemented (Liu et al., 2017, Martín et al., 2014, van Rees et al., 2014, Waongo et al., 2015). The primary adaptation measures arise from managing soil water more efficiently during the growing season by selecting cultivar, sowing time and density and fertilizer supply and timing (Ghahramani et al., 2015). Of these adaption strategies, variation in the sowing date and switching to alternative existing slowermaturing cultivars could be considered "autonomous adaptation" (Ding et al., 2016, Hasegawa et al., 2013), implemented by farmers without any exogenous input (e.g., policy intervention). Previous studies show that autonomous adaptations have the potential to benefit farmers in soil conservation and water management and are likely to improve agriculture in Australia (Ghahramani et al., 2015, Richards et al., 2014, van Rees et al., 2014). However, the productivity gains from the management strategies that are best for current climate conditions may not necessarily be robust to future climate conditions, which suggests that it is worthwhile examining adaptation techniques under projected future scenarios (Ghahramani et al., 2015).

We assessed climate-related changes in wheat production between 1961-2000 and 2041-2060 (hereafter "2050s") and 2081-2100 (hereafter "2090s") in the major wheatproducing states of Australia (New South Wales (NSW), Queensland (QLD), Victoria (VIC), South Australia (SA), Western Australia (WA)). We excluded Tasmania in our study because Tasmania is dominant by mountains and wheat growing area is very small (about $0.06 \%$ of Australian wheat area in 2005-2014, http://www.abs.gov.au/Agriculture). In contrast to most previous studies in Australia, we explicitly account for both changes in the area of cropland 
climatically suitable for growing wheat and changes in yields per hectare. We used localscale climate scenarios based on statistically downscaled data from 11 skill-selected Global Climate Models (GCMs) from the Coupled Model Intercomparison Project Phase 5 (CMIP5) multi-model ensemble (Taylor et al., 2012) and two Representative Concentration Pathways (RCP4.5 and RCP8.5) (Moss et al., 2010). Firstly, we used SDMs to assess changes in land area $\left(\mathrm{km}^{2}\right)$ of Australia climatically suitable for growing wheat for each climate scenario. We then employed the APSIM crop simulation model (Holzworth et al., 2014) to simulate impacts of climate change on wheat yields per hectare. We combined the results of the SDMs and APSIM analysis to assess climate-related changes in Australian wheat production. Finally, we ran APSIM simulations with different adaptation options including variation in the sowing date and switching to slower-maturing cultivars to investigate the effects of adaptation on future changes in national production.

\section{Materials and Methods}

APSIM (the Agricultural Production Systems Simulator) version 7.7 (http://www.apsim.info/) was used to model the impacts of climate change on grain yield. The simulation of wheat yield was performed for the 654 APSOIL wheat sites (Fig. S1a), where detailed soil profile data are available from the Australian Soil Resource Information Systems (http://www.asris.csiro.au/mapping/hyperdocs/APSRU/). Each soil file in APSIM model contains information including soil description, soil classification, site, region, latitude, longitude and data source, including the owner, project and experiment from which the data were derived (Dalgliesh et al., 2006). Each soil also has soil attributes including pH value $(\mathrm{pH})$, layer depth (Thick), bulk density (BD), saturated water content (SAT), drained upper limit (DUL) and crop specified lower limit (LL).

The APSIM simulations required downscaled daily temperature, rainfall and solar radiation data as inputs. The monthly data from which these daily data were derived were available for both RCP4.5 and RCP8.5 from 28 GCMs (Table S1) contributing to the Coupled Model Intercomparison Project Phase 5 (CMIP5) of the World Climate Research Programme (Taylor et al., 2012). Each of these GCMs simulates different future climate conditions for Australia for a specific RCP. We used output from multiple GCMs to sample this uncertainty. However, we disregarded GCMs that had inferior simulations of observed spatial patterns of climatological mean temperature and rainfall across Australia's wheat belt on the assumption that these would have inferior simulation of future climate changes. We 
used Taylor's diagram (Fig. S2) to assess GCMs. Specifically, we used skill scores according to Eq. (1) defined in Taylor's method (Taylor, 2001) in order to identify the relatively satisfactory GCMs in simulating the climatological temperature and rainfall over the Australian wheat belt (Wang et al., 2015). Of the 28 GCMs with sufficient data for the analysis, 11 achieved a skill score in Taylor's diagram greater than 0.8 for both annual mean daily minimum, daily maximum temperature and more than 0.4 for rainfall. These were selected for use in this study.

$$
S=\frac{4(1+R)^{2}}{\left(\frac{\sigma_{f}}{\sigma_{r}}+\frac{\sigma_{r}}{\sigma_{f}}\right)^{2}\left(1+R_{0}\right)^{2}}
$$

where $S$ is the skill score. $R$ is the spatial correlation coefficient in climatological mean values between the simulations and observations. $R_{0}$ is the maximum correlation coefficient attainable (here we use 0.999). $\sigma_{f}$ and $\sigma_{r}$ are the standard deviations of the simulated and observed spatial patterns in climatological means, respectively.

RCP4.5 and RCP8.5 simulations of the 11 skill-selected GCMs were downscaled for 8022 meteorological observing sites in Australia (Fig. S1b) using the statistical downscaling and bias-correction method of Liu and Zuo (2012). This method differs from many other statistical downscaling methods that require data involving atmospheric circulation or sea surface temperature as predictors, in that it uses GCM monthly climate data and historical observed data for the variables of interest. It can therefore be easily applied universally if a reliable daily historical climate record is available. Briefly, monthly GCM output data (solar radiation, rainfall, daily maximum and minimum temperature) from each GCM were interpolated to the observed sites using an inverse distance-weighted method. Biases were then corrected using a transfer function derived from the interpolated GCM data and observed data for the sites. Daily climate data for each site for 1900-2100 were generated by a modified stochastic weather generator (WGEN) (Richardson \& Wright, 1984) with parameters derived from the bias-corrected monthly data. Data for 1961-2000 were then used as a baseline climate against which to compare results for the future climate periods 20412060 (2050s) and 2081-2100 (2090s).

The use of different SDMs has been demonstrated to be an effective approach to improve the estimation of modelling through ensemble forecast techniques (Keenan et al., 2011). We used multiple SDMs to assess land climatically suitable for wheat cropping. By 
using a weighted ensemble mean of SDMs instead of a single model our analysis provided more robust and reliable assessment than previous studies using only one predictive species distribution model (Bunn et al., 2015, He \& Zhou, 2016, Ramirez-Cabral et al., 2016). We used ten species distribution models (SDMs) (Table S2) within the Biomod library (Thuiller, 2003, Thuiller et al., 2009) programmed in R software (R-Core-Team, 2016) to create statistical relationships between the wheat occurrence records and observed values of 21 environmental variables, including multi-year means of eleven climatic factors, six soilrelated factors, three topographical factors and one land cover factor, to constrain the model to existing cropland (Table 1). Spatial data for the 11 climate variables averaged over 19612000 were interpolated from observations at 8022 weather stations using the inverse distance weighing method across Australia. All spatial layers for predictors were rescaled to a resolution of 30 arc-seconds $(\sim 1 \mathrm{~km} \times 1 \mathrm{~km})$ using the R package "raster" (https://cran.rproject.org/web/packages/raster/raster.pdf).

In this study, we used 654 APSOIL data points (outlined above) as current climatically suitable sites for growing wheat. A range of environmental variables, including climate variables for these sites, were used as input of SDMs to evaluate the effect of climate change on current wheat growing areas. It is difficult to directly compare our SDM-predicted areas with previous studies due to different input data and model parameterisations with different SDMs. For example, how the outputs of global-scaled climate models are downscaled and whether input data (such as crop, soil, topographic and land cover) determining crop suitability are available across the region. We considered soil variables and land cover as predictors in determining crop suitability as they may have strengthened model predictions (Stanton et al., 2012). These environmental variables, however, were not considered in other previous studies probably due to lack of specific data (Evangelista et al., 2013, Ramirez-Cabral et al., 2016).

To calibrate and evaluate the SDMs, values of the 21 environmental values were extracted from the spatial layers for a set of 5830 sites for which the presence and absence of wheat for recent climate conditions is known. This set of sites comprised 654 sites in the APSOIL (Dalgliesh et al., 2006) database for which wheat is indicated as being present (Fig S1a), and 5176 sites outside Australia's grain belts (https://grdc.com.au/About-Us/GRDCAgroecological-Zones), for which wheat is assumed to be absent. Each of SDMs was calibrated using data from a random selection of $80 \%$ of these 5830 sites, with data for the remaining $20 \%$ of sites reserved for model evaluation. To sample uncertainties in model 
parameter values due to sampling of available data for training, the training and evaluation processes were repeated ten times for each of ten SDMs with a different random selection of sites.

The relative performance of the 100 combinations (10 SDMs with 10 replicates) and parameter value sets was evaluated by using the True Skill Statistic (TSS) to compare predicted and observed wheat presence at the validation sites. We retained the 90 SDM set ups that gave TSS > 0.7, eliminating all ten set ups of a single poorly performing SDM (Fig. S3). In subsequent analysis, results for each SDM set up were weighted according to TSS score; TSS-weighted results proved to have higher predictive power than results from unweighted SDM set ups, or even using the best set up (Keenan et al., 2011). Strong TSS evaluations, the area under the curve statistic of the receiver operating characteristic (AUC) and Kappa statistic evaluations (Fig. S3), lead us to conclude that the weighted ensemble mean for current climate conditions had strong model performance and predictability on wheat suitability across Australia's wheat belt (Fig. S3).

To analyse spatial changes in the climatic suitability for wheat for each RCP, we applied the 90 skill-selected SDM set ups to downscaled climate data for each of the 11 GCMs. The SDMs output suitability values between 0 and 1 at each grid cell. To obtain a best estimate of the absence or presence of wheat for the current, 2050s and 2090s time periods we first calculated the TSS-weighted means of the binary outputs from each of the 90 SDM set ups for each GCM. We then calculated an unweighted mean of the 11 GCM results and used a threshold (0.5) for the ensemble-mean value to determine the absence or presence of wheat. Change maps for the GCMs ensemble were produced by comparing the ensemblemean absence/presence data between current and future time periods and differentiating areas of gain, loss, and stable climate suitability (Evangelista et al., 2013).

However, the SDM-predicted area suitable for wheat not only covered actual wheat growing areas but also included areas used for nature conservation, forestry, water storage and urban development (Fig. S4). We therefore applied observed areas of wheat planting from Australian Bureau of Statistics (ABS) Agricultural Commodities (2005-2014) (http://www.abs.gov.au/Agriculture) to correct the SDMs-predicted areas.

$$
\alpha=\frac{A_{\text {wheat_base }}}{A_{\text {SDMs_base }}}
$$




$$
A_{\text {wheat_fu }}=\alpha \times A_{S D M s_{-} f u}
$$

where $A_{\text {wheat_base }}$ is the area of wheat based on ABS observations, a proxy for area of cropland where wheat was sown. $A_{S D M s_{-}}$base is the SDM-predicted area suitable for growing wheat under current climate conditions. $A_{S D M s_{-} f u}$ is the SDM-predicted area for the future climate and $A_{\text {wheat_fu }}$ is the corrected area for growing wheat.

The simulations of wheat yield per hectare used location-suitable cultivars, using existing APSIM-Wheat cultivar parameters for degree-day responses as well as cultivar sensitivity to vernalisation and photoperiod for various crop growth stages. The only difference between the simulated cultivars was in phenological response, and all other physiological parameters were the same between cultivars (Chenu et al., 2013, Ghahramani et al., 2015). In this study, we selected reference cultivars (Table S3) which are suitable for each location based on the crop variety sowing guide for each State in Australia (e.g. https://www.dpi.nsw.gov.au/agriculture/broadacre-crops/guides/publications/wintercrop-variety-sowing-guide). In addition, we considered the crop response to the elevated atmospheric $\mathrm{CO}_{2}$ concentration in APSIM by using an empirical equation as a function of calendar year (Liu et al., 2017, Wang et al., 2017b). For RCP4.5 scenario, the atmospheric $\mathrm{CO}_{2}$ concentration was calculated by:

$\left[\mathrm{CO}_{2}\right]_{\text {year }}=650.18+\frac{0.000075326 * \mathrm{y}-0.16276}{0.00022299-\frac{727.97}{\mathrm{y}^{2}}}-0.00018747 *(\mathrm{y}-2045)^{3}$

For RCP8.5, it was fitted by:

$$
\left[\mathrm{CO}_{2}\right]_{\text {year }}=1034.3+\frac{267.78-1.6188 * \mathrm{y}}{4.0143+\frac{53.342}{\mathrm{y}^{5.2822}}}+21.746 *\left(\frac{\mathrm{y}-2010}{100}\right)^{3}+100.65 *\left(\frac{\mathrm{y}-1911}{100}\right)^{3}
$$

To investigate climate change adaptation, we performed APSIM simulations sowing slow maturing cultivars that require more thermal time to mature. As the commencement of each phenological stage is mainly determined by thermal time (TT) accumulation calculated as degree days $\left({ }^{\circ} \mathrm{C}\right.$ d) in APSIM, we increased TT during the vegetative growth period to generate longer season types.

$$
\Delta T T=\tau * \Delta T * D T F
$$

where $\Delta T\left({ }^{\circ} \mathrm{C}\right)$ is the increased maximum value for mean temperature for each GCM scenario. DTF (Days To Flowering) is the length of the period from sowing to flowering for current 
climate conditions. $\tau(=0,0.2,0.4,0.8,1.0)$ is used generate a series of different possible genotypes with different $T T$. As an additional adaptation, for the baseline and each projected future climate, the sowing windows were progressively varied by 10-day increments from a maximum 40 days earlier to 40 days later than the reference dates. A factorial simulation experiment was conducted in which the factors were climate ( 2 scenarios $\times 11 \mathrm{GCMs})$, sites (654), and adaptation options (9 sowing offsets $\times 5 \tau(=0,0.2,0.4,0.8,1.0))$ These simulations were carried out to maximize the long-term average yield for each location $\times$ cultivar $($ increased $T T) \times$ sowing date $\times$ climate.

\section{Results}

Projected future climate change during wheat growing season

To present the range in projected future climate, mean changes across the selected 11 GCMs in mean temperature and rainfall during the wheat-growing season (April-November) for both RCPs were computed across each state and Australia. All GCMs agreed on a future temperature rise and, consistent with greater greenhouse forcing of the climate system and a close link between regional and global warming, RCP8.5 had higher temperature increases than RCP4.5. For example, between 1961-2000 and 2081-2100, the ensemble-mean temperature increase for the Australian wheat belt was $2.1{ }^{\circ} \mathrm{C}$ for RCP4.5 and $3.9{ }^{\circ} \mathrm{C}$ for RCP8.5 (Fig. la). The highest increase for temperature was located in NSW, with the regionally averaged ensemble mean increase of $1.9{ }^{\circ} \mathrm{C}$ for RCP4.5 and $3.1{ }^{\circ} \mathrm{C}$ for RCP8.5. The lowest projected increase was found in VIC, $1.7{ }^{\circ} \mathrm{C}$ for RCP4.5 and $2.8{ }^{\circ} \mathrm{C}$ for RCP8.5.

Changes in projected changes in growing season rainfall varied with GCM, with some GCMs simulating increases in rainfall and some simulating decreases. However, most of the GCMs projected decreases and the ensemble-mean changes in rainfall for the different regions considered were almost entirely decreases. Between 1961-2000 and 2081-2100, the ensemble-mean growing season rainfall change for the Australian wheat belt showed a similar decrease of $7.4 \%$ for RCP4.5 and a decrease of $7.5 \%$ for RCP8.5 probably because GCMs with increases and decreases were cancelling each other out (Fig. 1b). The largest ensemble-mean decrease in rainfall, $11.0 \%$ for RCP4.5 and $17.4 \%$ for RCP8.5, was found in WA (Fig. 1b). The smallest decrease, $1.2 \%$ and $1.3 \%$ for RCP4.5 and RCP8.5 respectively, was located in NSW. 
These climate projection results were generally consistent with recent climate projections for Australia produced by CSIRO and the Australian Bureau of Meteorology (2015) (CSIRO \& BoM, 2015).

\section{Projected climate suitability for wheat}

The most important variable for wheat distribution was the rainfall of the wettest month, followed by annual cumulative rainfall and maximum temperature of the warmest month (Fig. S5), which was consistent with the fact that crop distribution is mainly constrained by water conditions in this largely semi-arid environment (Chenu et al., 2013, Evangelista et al.,2013). A summary of the future changes in climatically suitable areas simulated by the multi-GCM, multi-SDM ensemble was shown in Fig. 2a (refer to Fig. S6-9 for each GCM and RCP at different time periods). The SDM-predicted areas suitable for wheat tended to shrink from the north with increased forcing of the climate system. The shifts were more pronounced under RCP8.5 than under RCP4.5 and more pronounced for the 2090s than for the 2050s. By the 2090s, the results showed areas suitable for growing wheat retreating in the northern part of the east Australian wheat belt and, to a lesser extent, in Western Australia, particularly under RCP8.5. In contrast, some southerly higher latitude areas not currently climatically suitable for wheat growth (e.g. in southwest Victoria), would become suitable.

The SDM-predicted areas for wheat under the current climate overestimated observed wheat planting areas (Fig. S4), so we corrected state and national SDM-predicted areas to obtain absolute values of cropland area suitable for wheat under future climate change (Table 2). The GCM ensemble-mean total wheat area over Australia was projected to decrease from 12.85 million hectares (Mha) for 1961-2000 to 12.29 Mha by the 2050s and 12.14 Mha by the 2090s for RCP4.5 and to 11.83 Mha by the 2050s and 10.99 Mha by the 2090s for RCP8.5. Fig. $2 b$ showed the projected relative changes in SDM-predicted area climatically suitable for growing wheat from 11 GCMs in Australia and five states. Our results showed that the largest ensemble-mean decrease in simulated wheat climate suitability was found in Queensland, especially under the high-emission RCP8.5 scenario, with a loss of up to $69.3 \%$ of climate suitability, followed by NSW. In contrast, South Australia and Victoria were projected to experience increases of climate suitability, and a small increase occurred in WA for most of scenarios except RCP8.5 which had a 15\% decrease by the 2090 s.

Projected change in yield per hectare with and without adaptation options 
APSIM simulations driven with climate data downscaled from the $11 \mathrm{GCMs}$ and accounting for increasing atmospheric $\mathrm{CO}_{2}$ concentrations were used to evaluate future changes in wheat yield per hectare at 654 representative sites (Fig. S1a). Fig. 3 showed percentage changes in yields averaged across all sites and sites in specific Australian states. The results for all sites across Australia showed multi-model mean wheat yields decreasing by the 2050s under RCP4.5, with a greater decrease occurring by the 2090s (Fig. 3). However, corresponding results for RCP8.5 showed less yield decrease because RCP8.5 was consistent with greater $\mathrm{CO}_{2}$ concentrations but associated increases in temperature would counteract the smaller positive impacts from elevated $\mathrm{CO}_{2}$. Results for individual Australian states varied. Queensland experienced the most significant reductions in yield, with all GCMs showing decreases even for RCP8.5 by the 2090s. In contrast, multi-GCM mean yields showed a tendency to increase in Victoria, except for RCP4.5 for the 2090s.

Using APSIM, we assessed the effect of autonomous adaptation on yields per hectare when the sowing date was shifted to earlier in the year and a longer season cultivar was used with respect to our cultivar-sowing date reference (Ghahramani et al., 2015, van Rees et al., 2014). Overall, the maximum yield was realized by bringing forward the wheat sowing date by approximately 11-18 days, and using a cultivar with a longer growth period (Fig. S10). The magnitude of adaptation required differed between states. Sowing date was shifted the most in WA compared with other states. The results of APSIM simulations with optimum adaptation of sowing dates and cultivar selection to maximize yield showed general improvement for Australian wheat yields. Multi-GCM mean changes were shown in Fig 3. The whole-of-Australia multi-GCM mean data for the 2050s showed an increase of $8.8 \%$ for RCP4.5 and an increase of $10.7 \%$ for RCP8.5. For the 2090s, yield changes increased $4.2 \%$ and $9.0 \%$ for RCP4.5 and RCP8.5 respectively. The simulated adaptations more than compensated for the negative impact of climate change on yields.

\section{Projected national wheat production change}

We combined the results of the SDMs analysis of areas climatically suitable for growing wheat with the APSIM simulated yields per hectare to assess changes in Australian wheat production. When these corrected areas were combined with APSIM-simulated yields per hectare, there was an overall decline in Australian wheat production in response to future climate change without adaptation. Multi-GCM mean results showed national wheat production decreasing by $6.7 \%$ by the 2050 s and $7.4 \%$ by the 2090 s under RCP 4.5 , decline 
by $9.1 \%$ by the 2050 s and $15.5 \%$ by the 2090 s under RCP8.5 (Fig. 4 ). The magnitude of decrease in production increased with greenhouse forcing of the climate system. However, our results showed that when autonomous adaptations were used, Australia's wheat production increased by $1.6-4.1 \%$ by the 2050s for the two RCPs (Fig. 4). Therefore, on midcentury time scales, changing sowing dates and selecting optimal cultivars were, according to our simulations, effective ways to maximise wheat production in the face of climate change. In contrast, in the longer term (2090s), these adaptations were insufficient to increase national wheat production, and may not fully offset the adverse impact of climate change under RCP8.5. Under this scenario, by the 2090s, less growing area offset any increase in yield due to $\mathrm{CO}_{2}$ fertilization and adaptations.

\section{Discussion}

Our analysis shows an overall tendency for the climatic suitability for wheat to decrease under future climate change, which concurs with results of other recent studies showing that Australia gradually loses suitability for crop growth (Grundy et al., 2016, Ramirez-Cabral et al., 2016). However, the magnitude of the changes depends on how climate change will affect local conditions and is therefore subject to a high degree of uncertainty related to GCM-based climate projections. It is noteworthy that nearly all of Australia's wheat depends on rainfall, particularly the amount of seasonal rainfall. The prediction of current wheat suitability further verified that seasonal rainfall and temperature are important variables for Australia (Fig. S4). Australia is likely to experience longer periods of drought and more intense rainfall extremes, and these projected changes are anticipated to increase substantially with greenhouse gas emissions and time (Alexander \& Arblaster, 2017). Despite varying degrees of uncertainty, national-scale climate change impacts on suitable areas for wheat provide useful information on shifts in production zones, which will be pivotal for developing early warning systems and adaptive strategies (e.g. guiding the focus of national wheat breeding programs seeking to develop better-adapted crop cultivars) as well as informing policy makers about locating infrastructure for access of production regions to road, ports and markets (Cleugh et al., 2011).

The major factors affecting the productivity of rainfed cropping systems include crop cultivar, agronomic management, climate and soil properties (Anwar et al., 2015). Our analyses of simulated wheat yield applied up to 654 soil sites and provided a comprehensive evaluation of climate change impacts across the whole Australian wheat belt. Wheat yield 
changes depended on climate conditions between states. Overall, wheat yield would benefit from future climate change in cool areas (Victoria) and suffer in warm regions especially in QLD. This is consistent with earlier studies in Victoria showing beneficial effects on wheat productivity in the southern parts of the state out to 2070 (O'Leary et al., 2011) and supports the idea that cooler areas may be able to increase the production and export of wheat. Our present results in Australia are also in accordance with a recent global wheat productivity study (Balkovič et al., 2014) that showed that global warming will result in higher yield only in colder climates. However, in many rainfed production systems, such as in parts of Central Asia and North America, the potential negative impacts of temperature cannot be fully offset by increased rainfall (Balkovič et al., 2014).

Our results also concur with recent studies based on experimental and modelling approaches that concluded that $\mathrm{CO}_{2}$ fertilization will significantly affect the future yield of wheat crops in the semi-arid Australian environment (Fitzgerald et al., 2016, O'Leary et al., 2015). Without the increase in $\mathrm{CO}_{2}$ concentration, simulated wheat yield would decrease remarkably for two RCPs in eastern Australia (Wang et al., 2017a). Global wheat production with $\mathrm{CO}_{2}$ fertilization was approximately $20 \%$ and $35 \%$ higher by 2050 s and 2090 s, respectively, compared to estimates that assumed climate change without $\mathrm{CO}_{2}$ fertilization (Balkovič et al., 2014). However, in almost all Australian states, the negative effects of increased temperatures and reduction in rainfall on wheat are not fully compensated for by the positive effects of increased $\mathrm{CO}_{2}$ concentrations (Hochman et al., 2017). This highlights the need for adaptation plans to cope with climate change. Across all states, our simulated results show that sowing a slow development cultivar earlier than current practice should be an effective management adaptation to increase grain yield. Recent evaluations of adapting to climate change in wheat farming systems indicate that there will be a greater opportunity to increase productivity of the Australian wheat belt, mostly because of elevated atmospheric $\mathrm{CO}_{2}$ concentrations resulting in increased water use (Ghahramani et al., 2015). Earlier sowing is currently being promoted by many farmers as a method to adapt to climate change by shifting the wheat growing season to a wetter and cooler part of the year to increase water use efficiency. Switching to a long-season cultivar is also a promising adaptation option. These slower developing (in present climate) cultivars have a theoretical yield advantage over faster maturing cultivars as they have a long growth cycle that resists the shortening of the growing season as the temperature rises (Martín et al., 2014, Wang \& Connor, 1996). Although they have been suggested as an effective adaptation to mitigate climate change, 
they must be managed well to flower at the optimum time, avoid frosts on one hand and later heat extremes during flowering (Barlow et al., 2015, van Rees et al., 2014, Zheng et al., 2012), and avoid the possibility of producing high biomass crops unable to complete grain filling owing to lack of water during the reproductive stages of growth.

The wheat-growing regions of the world have been categorized into $17 \mathrm{Mega}$ Environments (MEs) based on different agro-climatological parameters by the international wheat-breeding network facilitated by the International Maize and Wheat Improvement Center (CIMMYT) (Gbegbelegbe et al., 2017). These agro-ecological zones are the target breeding areas that represent various environmental conditions. The wheat crop in Australia is almost entirely contained within rainfed ME4 that is relevant to northern Africa, Chile and the north-east to Argentina (http://aciar.gov.au/files/mn-158/s3_5-australia.html). Therefore, the methods used here can be applied to those similar wheat growing areas in CIMMYT, which will offer the possibility of re-evaluating global agricultural capacity under future climate conditions.

Climate change impact assessment in our study provides an overview which gains an understanding of the impacts in Australian wheat production today and into the future through adapting Australia's wheat cropping systems. Our results show that autonomous adaptation measures will remain important for enhanced wheat yield and provide significant mitigation of the negative effects of climate change on national wheat production in the near future. From such research, there have been many lessons for rainfed cropping regions. For example, there are also decreasing spatial trends in cereal production in Ethiopia due to changes in rainfall and temperature and therefore the ability to adapt to climate change will be critical for Ethiopia's agricultural system (Evangelista et al., 2013). Rurinda et al. (2015) suggested that there will be no effective farm management options that can avoid yield loess due to climate change in southern Africa towards the end of the 21 st century, and thus transforming current cropping systems was required to offset the negative impacts of future climate change.

Our study has not investigated all adaptation options comprehensively. Instead, we focused our analysis of adaptation on productivity (yield per hectare) and did not consider all the possible non-climatic factors that impact the area of cropland suitable for growing wheat. It is conceivable that switching to cultivars that are more resistant to heat and drought stress may also slow the retreat of wheat growing areas in the northern Australian wheat belt. 
Accounting for the beneficial impact of $\mathrm{CO}_{2}$ increases on water use efficiency could also affect changes in areas of cropland suitability for growing wheat. In addition, the rate at which farmers will adapt to changing climatic conditions is highly uncertain. Therefore, the autonomous approach should be combined with non-autonomous adaptation strategies, such as targeted advances in crop breeding, agronomy, soil water conservation and seasonal climate forecasting (Ainsworth et al., 2008). However, as the first step our study only focused on the effects of autonomous adaptation measures to climate change. Future work needs to be concentrated on interactions between genotypes, environments and management to mitigate adverse impacts from climate extreme events (e.g. drought and heat stress) and climate variability.

Another limitation of our methodology is that we only provide simulation results from one crop model. These shortcoming may be overcome to some extent by comparing results from several crop growth models, which use the same combination of climate, soil, management and other input data (Martre et al., 2015). The wheat pilot study of the recent agricultural model inter-comparison and improvement project (AgMIP) has examined (and narrowed) differences between results from different crop models through systematic model inter-comparison. It found considerable variation in projected impacts among crop models due to differences in model structures and parameter values (Asseng et al., 2013, Rosenzweig et al., 2013). It is not surprising that the sheer complexity of agricultural systems is difficult to reproduce accurately in numerical models (Wheeler \& Von Braun, 2013). It is also worth noting that the effects of economic feedbacks and risk profiles were not considered because of their complexity across the diverse Australian continent. Further, the incorporation of such technological progress and socio-economic feedback would require much more comprehensive model capacity. Even the most sophisticated models may not have all the critical factors covered so continued field and laboratory experimentation as well as social and economic analysis to further develop modelling is essential.

Increasing Australian wheat production is essential to meet increasing national and international demand and maintain Australia's contribution to global food security. Understanding the possible impact of climate change and adaptation options for Australian food production is essential to inform public debate and policy makers to maintain wheat exports and contribute to the global wheat market. We believe that the results of this study can help local government, industry leaders and farmers to make effective adapted agricultural management decisions today while anticipating future climate change impacts. 
The maps of wheat suitability provide insights and guidance on where wheat is likely to suffer the most and the least under future climate change. However, maintaining future production gains will require more improved use of technologies and practices beyond autonomous adaptation to cope with climate change. For example, Martín et al. (2014) found that genetic modification regarding wheat crop development exhibited the greatest sensitivity to climate change and larger potential for improvement in Europe. New wheat cultivars might provide more drought and heat resistance against droughts and warming conditions. Results from the modelling of crops with different thermal time requirements will assist selection of promising genotypes based on multiple-target breeding programmes.

Timely and effective adaptation will likely bring opportunities and significant national benefits for Australia (Ghahramani et al., 2015). Yet it is unclear whether national total wheat production would remain unchanged or increase with future climate change when adaptation strategies are adopted. To attempt to answer this question, we applied species distribution models to investigate future changes in areas climatically suitable for growing wheat in Australia. A crop model was then used to assess wheat yield per hectare change in these areas under future climate change. We concluded that the climatically suitable areas for wheat are likely to decrease, especially in the north-eastern Australian wheat belt under large greenhouse forcing of the climate system, such as under RCP8.5 in the 2090s. Higher latitudes should become more suitable than at present, and will continue to be highly suitable for producing wheat. Our crop model simulation results without adaptation are consistent with earlier simulation studies that showed likely wheat yield decreases of 2.0-6.0\% in Australia from comparable scenarios. Though an analysis using a mix of field experiments and a range of suitable crop models would be necessary to confirm these results, $\mathrm{CO}_{2}$ fertilization and adaptive management appear to provide significant mitigation of the negative effects of climate change in the middle 21 st century. However, these positive effects would result in limited improvement for national production of wheat in the late 21 st century. It is likely that decreased suitable Australian wheat growing areas under RCP8.5 in the late 21 st century will exceed yield response even considering autonomous adaptation to maximise yield.

\section{Acknowledgements}

The first author acknowledges that the NSW Department of Industry provided office facilities for conducting this work. We acknowledge the World Climate Research 
Programme's Working Group on Coupled Modelling, which is responsible for CMIP, and we thank the climate modelling groups (listed in Table S1 of supplementary information) for producing and making available their model output. For CMIP the U.S. Department of Energy's Program for Climate Model Diagnosis and Intercomparison provides coordinating support and led development of software infrastructure in partnership with the Global Organization for Earth System Science Portals. Thanks to Ms. Qinggaozi Zhu at UTS for downloading soil property data. We are very grateful to two reviewers for their very thorough and helpful comments which greatly improved our manuscript.

\section{References}

Ainsworth EA, Beier C, Calfapietra C et al. (2008) Next generation of elevated [CO2] experiments with crops: a critical investment for feeding the future world. Plant, Cell \& Environment, 31, 1317-1324.

Alexander LV, Arblaster JM (2017) Historical and projected trends in temperature and precipitation extremes in Australia in observations and CMIP5. Weather and Climate Extremes, 15, 34-56.

Anwar MR, Liu DL, Farquharson R et al. (2015) Climate change impacts on phenology and yields of five broadacre crops at four climatologically distinct locations in Australia. Agricultural systems, 132, 133-144.

Asseng S, Ewert F, Rosenzweig C et al. (2013) Uncertainty in simulating wheat yields under climate change. Nature Climate Change, 3, 827-832.

Balkovič J, Van Der Velde M, Skalský R et al. (2014) Global wheat production potentials and management flexibility under the representative concentration pathways. Global and Planetary Change, 122, 107-121.

Barlow K, Christy B, O’leary G, Riffkin P, Nuttall J (2015) Simulating the impact of extreme heat and frost events on wheat crop production: A review. Field crops research, 171, 109-119.

Bunn C, Läderach P, Rivera OO, Kirschke D (2015) A bitter cup: climate change profile of global production of Arabica and Robusta coffee. Climatic Change, 129, 89-101. 
Chenu K, Deihimfard R, Chapman SC (2013) Large-scale characterization of drought pattern: a continent-wide modelling approach applied to the Australian wheatbelt-spatial and temporal trends. New Phytologist, 198, 801-820.

Cleugh H, Smith MS, Battaglia M, Graham P (2011) Climate change: science and solutions for Australia, CSIRO.

Csiro, Bom (2015) Climate Change in Australia Information for Australia's Natural Resource Management Regions: Technical Report, CSIRO and Bureau of Meteorology, Australia.

Dalgliesh N, Wockner G, Peake A (2006) Delivering soil water information to growers and consultants. In: Proceedings of the 13th Australian Agronomy Conference, 10-14 September 2006, Perth, Western Australia. pp Page.

Ding D, Feng H, Zhao Y, Liu W, Chen H, He J (2016) Impact assessment of climate change and later-maturing cultivars on winter wheat growth and soil water deficit on the Loess Plateau of China. Climatic Change, 1-15.

Elith J, Leathwick JR (2009) Species distribution models: ecological explanation and prediction across space and time. Annual Review of Ecology, Evolution, and Systematics, 40, 677.

Evangelista P, Young N, Burnett J (2013) How will climate change spatially affect agriculture production in Ethiopia? Case studies of important cereal crops. Climatic Change, 119, 855-873.

Faostat (2014) Food and agricultural commodities production/countries by commodity. See http://faostat3.fao.org/browse/rankings/.

Fitzgerald G, Tausz M, O'leary G et al. (2016) Elevated atmospheric $\left[\mathrm{CO}_{2}\right]$ can dramatically increase wheat yields in semi-arid environments and buffer against heat waves. Global Change Biology, 22, 2269-2284. 
Gbegbelegbe S, Cammarano D, Asseng S et al. (2017) Baseline simulation for global wheat production with CIMMYT mega-environment specific cultivars. Field crops research, 202, 122-135.

Ghahramani A, Kokic PN, Moore AD, Zheng B, Chapman SC, Howden MS, Crimp SJ (2015) The value of adapting to climate change in Australian wheat farm systems: farm to cross-regional scale. Agriculture, Ecosystems \& Environment, 211, 112-125.

Godden D, Batterham R, Drynan R (1998) Climate change and Australian wheat yield. Nature, 391, 447-448.

Grundy MJ, Bryan BA, Nolan M, Battaglia M, Hatfield-Dodds S, Connor JD, Keating BA (2016) Scenarios for Australian agricultural production and land use to 2050.

Agricultural systems, 142, 70-83.

Hasegawa T, Fujimori S, Shin Y, Takahashi K, Masui T, Tanaka A (2013) Climate change impact and adaptation assessment on food consumption utilizing a new scenario framework. Environmental science \& technology, 48, 438-445.

He Q, Zhou G (2016) Climate-associated distribution of summer maize in China from 1961 to 2010. Agriculture, Ecosystems \& Environment, 232, 326-335.

Hochman Z, Gobbett DL, Horan H (2017) Climate trends account for stalled wheat yields in Australia since 1990. Global Change Biology, 23, 2071-2081.

Holzworth DP, Huth NI, Zurcher EJ et al. (2014) APSIM-evolution towards a new generation of agricultural systems simulation. Environmental Modelling \& Software, 62, 327-350.

Ipcc (2013) Climate Change 2013: The Physical Science Basis. Contribution of Working Group I to the Fifth Assessment Report of the Intergovernmental Panel on Climate Change [Stocker, T. F., D. Qin, G.-K. Plattner, M. Tignor, S. K. Allen, J. Boschung, A. Nauels, Y. Xia,V. Bex and P. M. Midgley (eds.)]. Cambridge University Press, Cambridge, United Kingdom and New York, NY, USA. 
Keating BA, Herrero M, Carberry PS, Gardner J, Cole MB (2014) Food wedges: Framing the global food demand and supply challenge towards 2050. Global Food Security, 3, 125-132.

Keenan T, Maria Serra J, Lloret F, Ninyerola M, Sabate S (2011) Predicting the future of forests in the Mediterranean under climate change, with niche-and process-based models: $\mathrm{CO}_{2}$ matters! Global Change Biology, 17, 565-579.

Lawrence G, Richards C, Lyons K (2013) Food security in Australia in an era of neoliberalism, productivism and climate change. Journal of Rural Studies, 29, 30-39.

Liu C, White M, Newell G, Griffioen P (2013a) Species distribution modelling for conservation planning in Victoria, Australia. Ecological modelling, 249, 68-74.

Liu DL, Zeleke KT, Wang B, Macadam I, Scott F, Martin RJ (2017) Crop residue incorporation can mitigate negative climate change impacts on crop yield and improve water use efficiency in a semiarid environment. European Journal of Agronomy, 85, 51-68.

Liu DL, Zuo H (2012) Statistical downscaling of daily climate variables for climate change impact assessment over New South Wales, Australia. Climatic Change, 115, 629-666.

Liu J, Folberth C, Yang H, Röckström J, Abbaspour K, Zehnder AJ (2013b) A global and spatially explicit assessment of climate change impacts on crop production and consumptive water use. PloS one, 8, e57750.

Ludwig F, Asseng S (2006) Climate change impacts on wheat production in a Mediterranean environment in Western Australia. Agricultural systems, 90, 159-179.

Martín MM-S, Olesen JE, Porter JR (2014) A genotype, environment and management (GxExM) analysis of adaptation in winter wheat to climate change in Denmark. Agricultural and Forest Meteorology, 187, 1-13.

Martre P, Wallach D, Asseng S et al. (2015) Multimodel ensembles of wheat growth: many models are better than one. Global Change Biology, 21, 911-925. 
Moss RH, Edmonds JA, Hibbard KA et al. (2010) The next generation of scenarios for climate change research and assessment. Nature, 463, 747-756.

O'leary G, Christy B, Weeks A, Nuttall J, Riffkin P, Beverly C, Fitzgerald G (2011) Downscaling Global Climatic Predictions to the Regional Level: A Case Study of Regional Effects of Climate Change on Wheat Crop Production in Victoria, Australia. In: Crop Adaptation to Climate Change. pp Page., Wiley-Blackwell.

O'leary GJ, Christy B, Nuttall J et al. (2015) Response of wheat growth, grain yield and water use to elevated $\mathrm{CO}_{2}$ under a Free-Air $\mathrm{CO}_{2}$ Enrichment (FACE) experiment and modelling in a semi-arid environment. Global Change Biology, 21, 2670-2686.

Qureshi ME, Hanjra MA, Ward J (2013) Impact of water scarcity in Australia on global food security in an era of climate change. Food Policy, 38, 136-145.

R-Core-Team (2016) R: A language and environment for statistical computing. R Foundation for Statistical Computing, Vienna, Austria.(https://www.r-project.org/). pp Page.

Ramirez-Cabral NYZ, Kumar L, Taylor S (2016) Crop niche modeling projects major shifts in common bean growing areas. Agricultural and Forest Meteorology, 218, 102-113.

Richards R, Hunt J, Kirkegaard J, Passioura J (2014) Yield improvement and adaptation of wheat to water-limited environments in Australia-a case study. Crop and Pasture Science, 65, 676-689.

Richardson CW, Wright DA (1984) WGEN: A model for generating daily weather variables. ARS (USA).

Rosenzweig C, Jones J, Hatfield J et al. (2013) The agricultural model intercomparison and improvement project (AgMIP): protocols and pilot studies. Agricultural and Forest Meteorology, 170, 166-182.

Rurinda J, Wijk MT, Mapfumo P, Descheemaeker K, Supit I, Giller KE (2015) Climate change and maize yield in southern Africa: what can farm management do? Global Change Biology, 21, 4588-4601. 
Schmidhuber J, Tubiello FN (2007) Global food security under climate change. Proceedings of the National Academy of Sciences, 104, 19703-19708.

Shabani F, Kumar L, Solhjouy-Fard S (2016) Variances in the projections, resulting from CLIMEX, Boosted Regression Trees and Random Forests techniques. Theoretical and applied climatology, 1-14.

Stanton JC, Pearson RG, Horning N, Ersts P, Reşit Akçakaya H (2012) Combining static and dynamic variables in species distribution models under climate change. Methods in Ecology and Evolution, 3, 349-357.

Taylor KE (2001) Summarizing multiple aspects of model performance in a single diagram. Journal of Geophysical Research: Atmospheres (1984-2012), 106, 7183-7192.

Taylor KE, Stouffer RJ, Meehl GA (2012) An overview of CMIP5 and the experiment design. Bulletin of the American Meteorological Society, 93, 485-498.

Thuiller W (2003) BIOMOD-optimizing predictions of species distributions and projecting potential future shifts under global change. Global Change Biology, 9, 1353-1362.

Thuiller W, Lafourcade B, Engler R, Araújo MB (2009) BIOMOD-a platform for ensemble forecasting of species distributions. Ecography, 32, 369-373.

Urban DW, Sheffield J, Lobell DB (2015) The impacts of future climate and carbon dioxide changes on the average and variability of US maize yields under two emission scenarios. Environmental Research Letters, 10, 045003.

Van Rees H, Mcclelland T, Hochman Z, Carberry P, Hunt J, Huth N, Holzworth D (2014) Leading farmers in South East Australia have closed the exploitable wheat yield gap: Prospects for further improvement. Field crops research, 164, 1-11.

Wang B, Liu DL, Asseng S, Macadam I, Yang X, Yu Q (2017a) Spatiotemporal changes in wheat phenology, yield and water use efficiency under the CMIP5 multimodel ensemble projections in eastern Australia. Climate Research, 72, 83-99.

Wang B, Liu DL, Asseng S, Macadam I, Yu Q (2015) Impact of climate change on wheat flowering time in eastern Australia. Agricultural and Forest Meteorology, 209, 11-21. 
Wang B, Liu DL, Asseng S, Macadam I, Yu Q (2017b) Modelling wheat yield change under $\mathrm{CO} 2$ increase, heat and water stress in relation to plant available water capacity in eastern Australia. European Journal of Agronomy, 90, 152-161.

Wang B, Liu DL, Asseng S, Macadam I, Yu Q (2017c) Spatiotemporal changes of wheat phenology, yield and water use efficiency under the CMIP5 multimodel ensemble projections in eastern Australia. Climate Research (in press).

Wang YP, Connor DJ (1996) Simulation of optimal development for spring wheat at two locations in southern Australia under present and changed climate conditions. Agricultural and Forest Meteorology, 79, 9-28.

Waongo M, Laux P, Kunstmann H (2015) Adaptation to climate change: The impacts of optimized planting dates on attainable maize yields under rainfed conditions in Burkina Faso. Agricultural and Forest Meteorology, 205, 23-39.

Wheeler T, Von Braun J (2013) Climate change impacts on global food security. Science, 341, 508-513.

Workman D (2017) Wheat Exports by Country (http://www.worldstopexports.com/wheatexports-country/). Accessed on May 9, 2017.

Yang X, Chen F, Lin X et al. (2015) Potential benefits of climate change for crop productivity in China. Agricultural and Forest Meteorology, 208, 76-84.

Zheng B, Chenu K, Fernanda Dreccer M, Chapman SC (2012) Breeding for the future: what are the potential impacts of future frost and heat events on sowing and flowering time requirements for Australian bread wheat (Triticum aestivium) varieties? Global Change Biology, 18, 2899-2914. 
Table 1. List of 21 environmental predictors for SDMs used in this study.

\begin{tabular}{|c|c|c|}
\hline Variable & Abbrev. & Units \\
\hline Annual mean temperature & MT & ${ }^{\circ} \mathrm{C}$ \\
\hline Mean Diurnal Range & MDR & ${ }^{\circ} \mathrm{C}$ \\
\hline Max Temperature of Warmest Month & MTWM & ${ }^{\circ} \mathrm{C}$ \\
\hline Min Temperature of Coldest Month & MTCM & ${ }^{\circ} \mathrm{C}$ \\
\hline Temperature Range (MTWM-MTCW) & TR & ${ }^{\circ} \mathrm{C}$ \\
\hline Isothermality (MDR/TR) (* 100) & $\mathrm{TS}$ & $\%$ \\
\hline Frost days (daily minimum temperature $<2{ }^{\circ} \mathrm{C}$ ) & FD & days \\
\hline Heat days (daily maximum temperature $>30{ }^{\circ} \mathrm{C}$ ) & $\mathrm{HD}$ & days \\
\hline Annual cumulative rainfall & $\mathrm{CP}$ & $\mathrm{mm}$ \\
\hline Rainfall of Wettest Month & PWM & $\mathrm{mm}$ \\
\hline Rainfall of Driest Month & PDM & $\mathrm{mm}$ \\
\hline 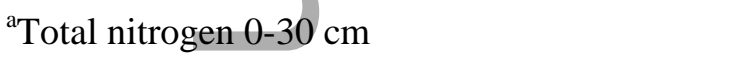 & NTO & $\%$ \\
\hline 'Total phosphorus 0-30 cm & PTO & $\%$ \\
\hline${ }^{\mathrm{b}}$ Clay content percentage $0-30 \mathrm{~cm}$ & CLY & $\%$ \\
\hline${ }^{\mathrm{b}}$ Bulk density & $\mathrm{BD}$ & $\operatorname{Mg~m}^{-3}$ \\
\hline${ }^{\mathrm{b}} \mathrm{pH}$ (Calcium Chloride 1:5) $0-30 \mathrm{~cm}$ & $\mathrm{pH}$ & \\
\hline${ }^{\mathrm{b}}$ Plant available water capacity $0-1 \mathrm{~m}$ & PAWC & $\mathrm{mm}$ \\
\hline${ }^{\mathrm{c}}$ Land cover & $\mathrm{LC}$ & \\
\hline Altitude & ALT & $\mathrm{m}$ \\
\hline Aspect & ASP & $\circ$ \\
\hline Slope & SLP & \\
\hline
\end{tabular}

${ }^{\mathrm{a}} \mathrm{See} \mathrm{http://www.clw.csiro.au/aclep/soilandlandscapegrid/ViewData-QuickView.html}$

${ }^{\mathrm{b}} \mathrm{See}$ http://www.asris.csiro.au/themes/NationalGrids.html

${ }^{c}$ See http://www.ga.gov.au/metadata-gateway/metadata/record/gcat_19b3b236-e0aa-d2fb-e05310a3070af790/Dynamic+Land+Cover+Dataset+Version+2 
Table 2. Multi-GCM mean (minimum and maximum range over $11 \mathrm{GCMs}$ ) of projected corrected area suitable for growing wheat (million hectare) under RCP4.5 and RCP8.5 for 2050s (2041-2060) and 2090s (2081-2100) in Australia and five different states. The SDMspredicted area climatically suitable for growing wheat under current climate was adjusted to 3.70, 0.81, 1.56, 2.12, 4.66 and 12.85 million hectare for NSW, QLD, VIC, SA, WA and AUS, respectively, which were based on ABS observed annual mean data (20052014, http://www.abs.gov.au/Agriculture).

\begin{tabular}{|c|c|c|c|c|}
\hline \multirow{2}{*}{ States } & \multicolumn{2}{|c|}{ RCP4.5 } & \multicolumn{2}{|c|}{ RCP8.5 } \\
\hline & $2050 \mathrm{~s}$ & $2090 \mathrm{~s}$ & $2050 \mathrm{~s}$ & $2090 \mathrm{~s}$ \\
\hline NSW & $3.65(2.96$ to 4.19$)$ & $3.47(2.72$ to 4.38$)$ & $3.42(2.96$ to 4.19$)$ & 3.09 (1.95 to 4.27$)$ \\
\hline QLD & $0.42(0.20$ to 0.75$)$ & $0.41(0.18$ to 1.07$)$ & $0.35(0.21$ to 0.64$)$ & 0.15 (0.08 to 0.32$)$ \\
\hline VIC & $1.70(1.60$ to 1.93$)$ & $1.76(1.59$ to 1.88$)$ & $1.72(1.53$ to 1.95$)$ & 1.92 (1.57 to 2.17$)$ \\
\hline SA & 2.33 (1.99 to 2.63$)$ & $2.27(1.84$ to 2.76$)$ & $2.30(1.90$ to 2.48$)$ & $2.51(1.71$ to 3.61$)$ \\
\hline WA & $4.77(4.38$ to 5.20$)$ & $4.86(4.20$ to 5.70$)$ & $4.75(4.25$ to 5.53$)$ & $4.22(3.24$ to 5.27$)$ \\
\hline AUS & $12.29(10.84$ to 13.38$)$ & 12.14 (9.98 to 14.67$)$ & $11.83(10.08$ to 13.28$)$ & $10.99(8.28$ to 13.72$)$ \\
\hline
\end{tabular}

\section{Figure captions:}

Figure 1. Projected changes in wheat growing season (April-November) (a) mean temperature (b) rainfall from 11 CMIP5 GCMs in Australia and five different states for RCP4.5 and RCP8.5 by 2050s (2041-2060) and 2090s (2081-2100) compared to 1961-2000. Box boundaries indicate the 25th and 75th percentiles across GCMs, whiskers below and above the box indicate the 10th and 90th percentiles. The black lines and crosshairs within each box indicate the multi-model median and mean respectively.

Figure 2. (a) Projected spatial changes in SDMs-predicted wheat suitable area from an ensemble mean of 11 CMIP5 GCMs. Changes are for RCP4.5 and RCP8.5 for 2050s (20412060) and 2090s (2081-2100) compared to baseline (1961-2000). Grey=no change (unsuitable), Blue=areas becoming suitable, Red=areas becoming unsuitable, Green=no change (suitable); red and green areas together make up the suitable area for 1961-2000. (b) Projected changes in wheat climate suitability in Australia and five different states for different scenarios. Box boundaries indicate the 25th and 75 th percentiles across GCMs, 
whiskers below and above the box indicate the 10th and 90th percentiles. The black lines and crosshairs within each box indicate the multi-model median and mean respectively.

Figure 3. Projected changes in APSIM-simulated wheat yield per hectare from 11 CMIP5 GCMs. Changes averaged across all sites in Australia and in five different states for RCP4.5 and RCP8.5 for 2050s (2041-2060) and 2090s (2081-2100) compared to 1961-2000. Box boundaries indicate the 25th and 75th percentiles across GCMs, whiskers below and above the box indicate the 10th and 90th percentiles. The black lines and crosshairs within each box indicate the multi-model median and mean respectively. Black rectangles represent multimodel mean values from simulations with optimum adaptation.

Figure 4. Projected changes in Australian wheat production from 11 CMIP5 GCMs. Changes are for RCP4.5 and RCP8.5 for 2050s (2041-2060) and 2090s (2081-2100) compared to 1961-2000. Box boundaries indicate the 25th and 75th percentiles across GCMs, whiskers below and above the box indicate the 10th and 90th percentiles. The red lines and black crosshairs within each box indicate the multi-model median and mean respectively. Black rectangles represent multi-model mean values from simulations with optimum adaptation.

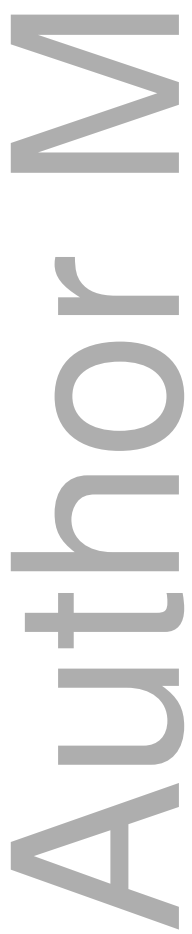



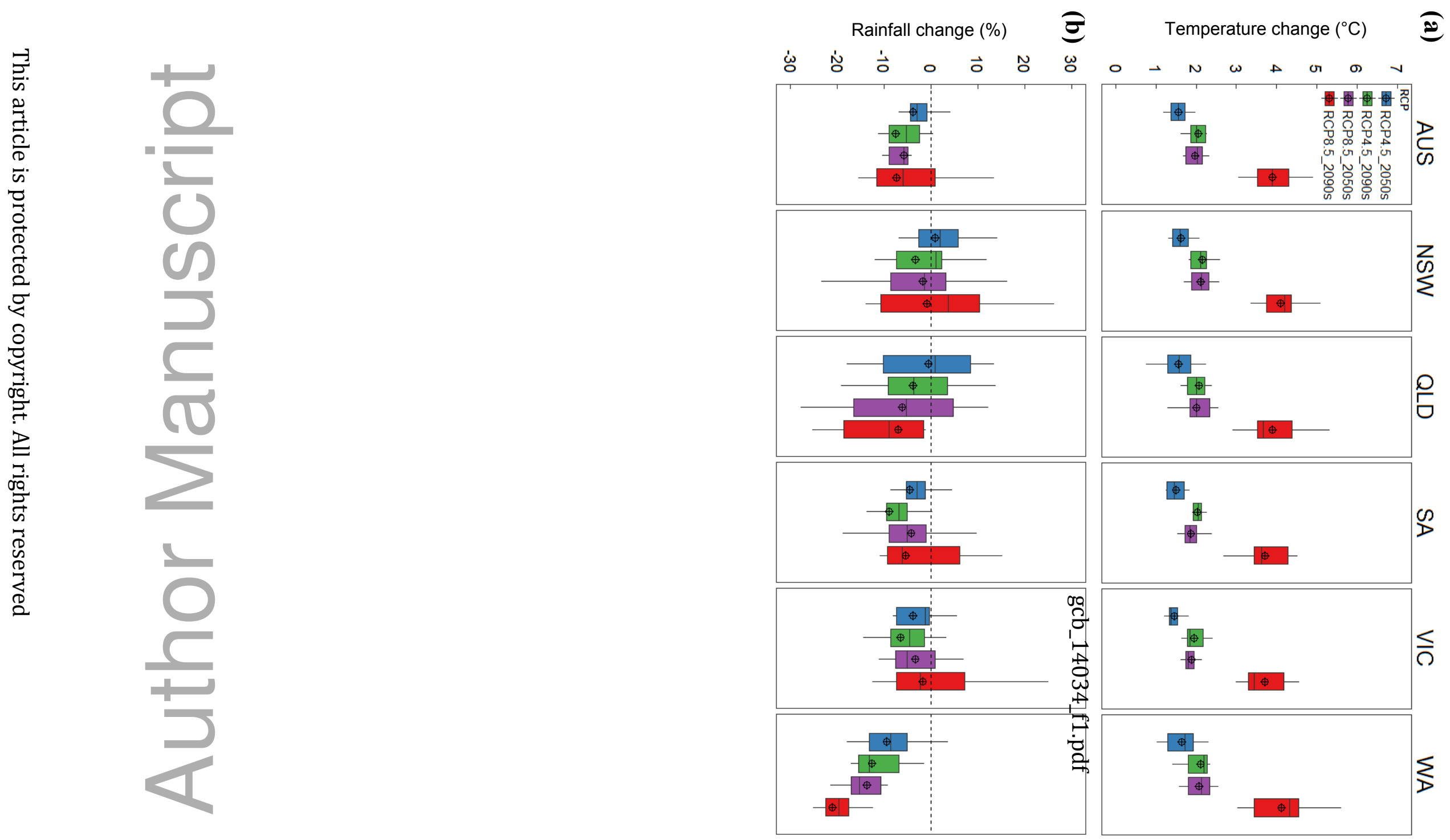
(a)
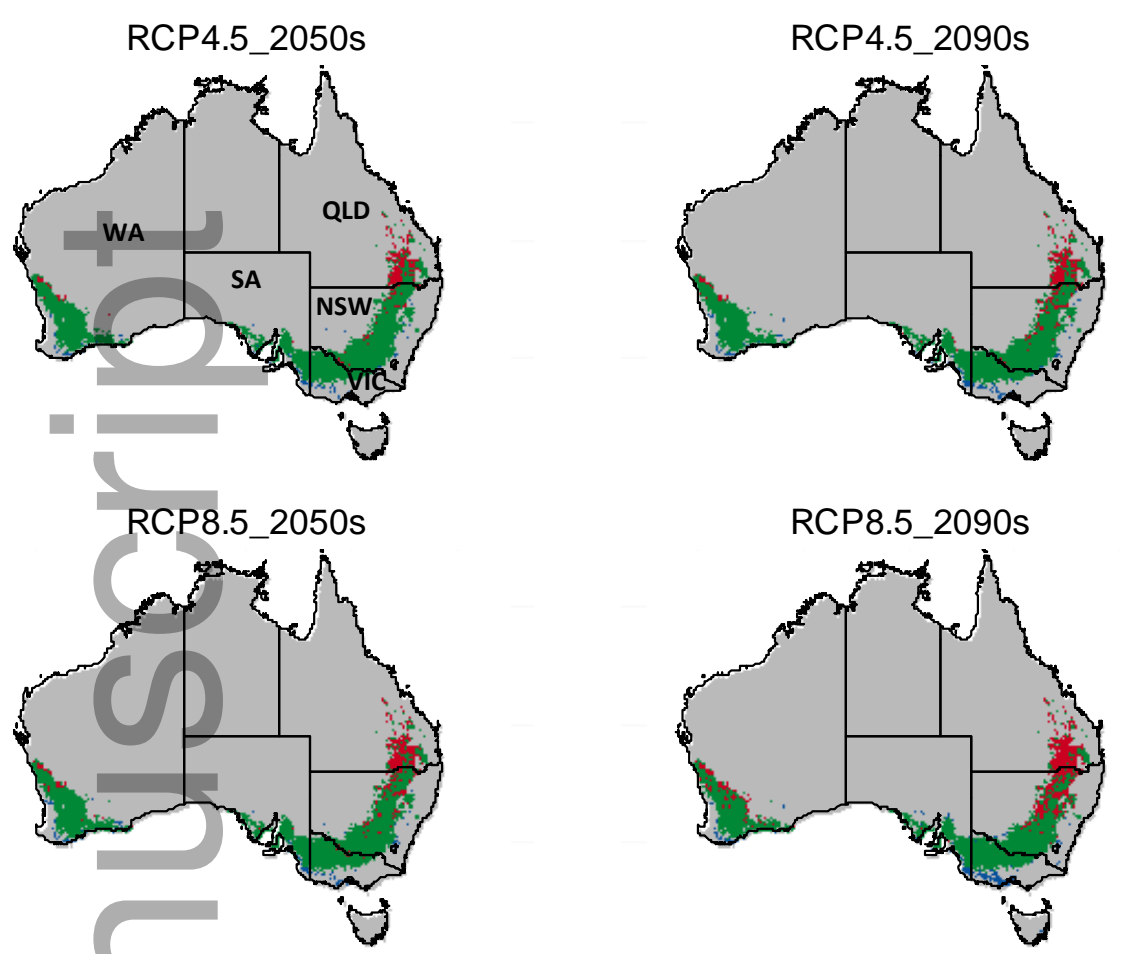

(b)

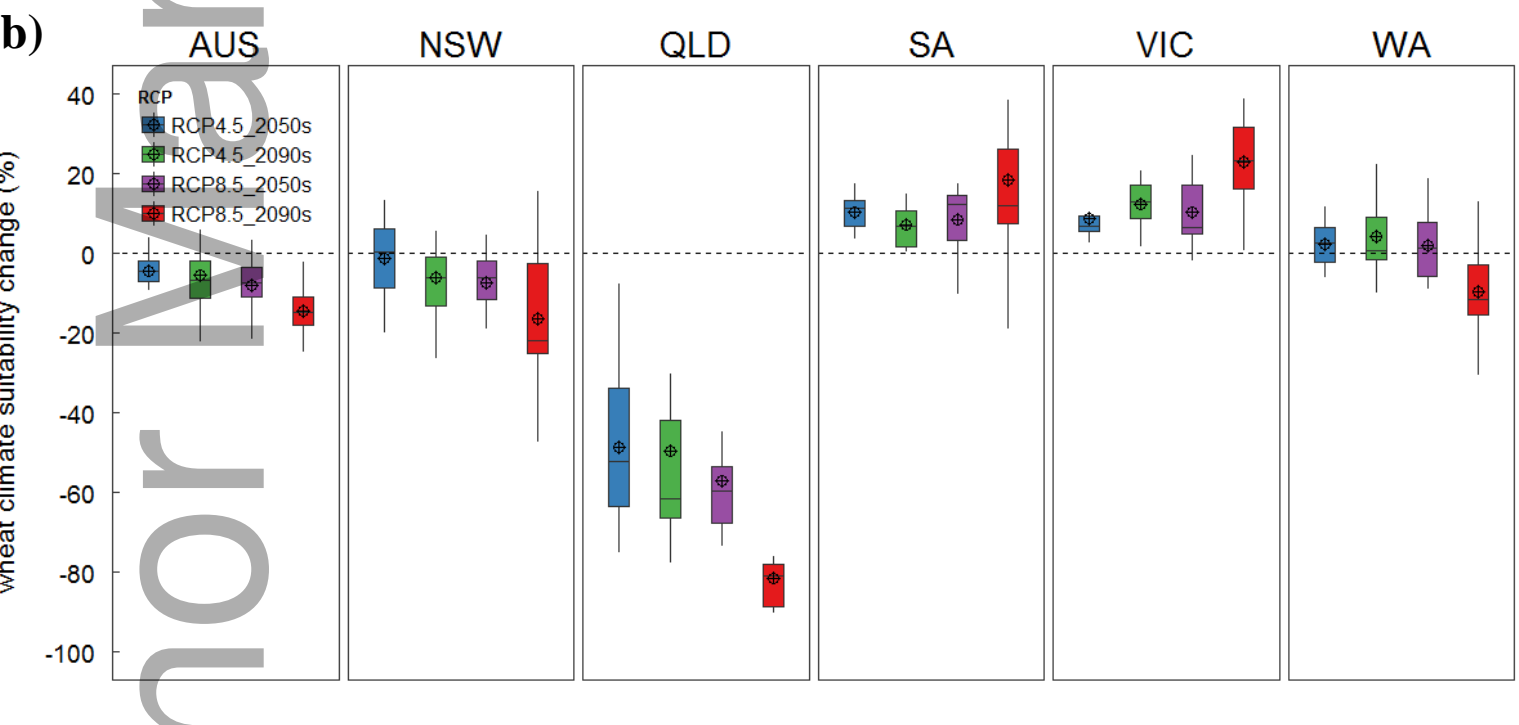

This article is protected by copyright. All rights reserved 

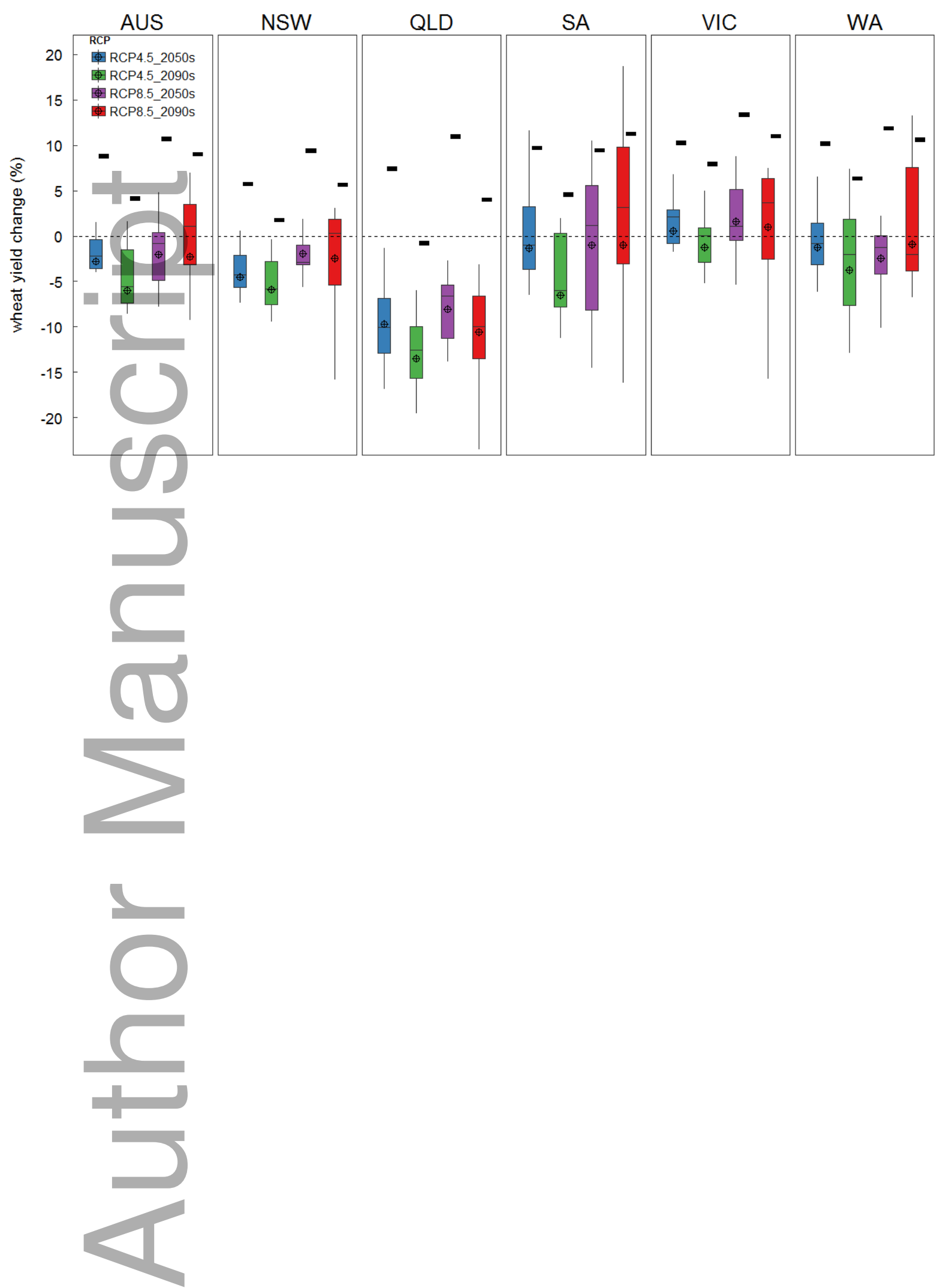

This article is protected by copyright. All rights reserved 

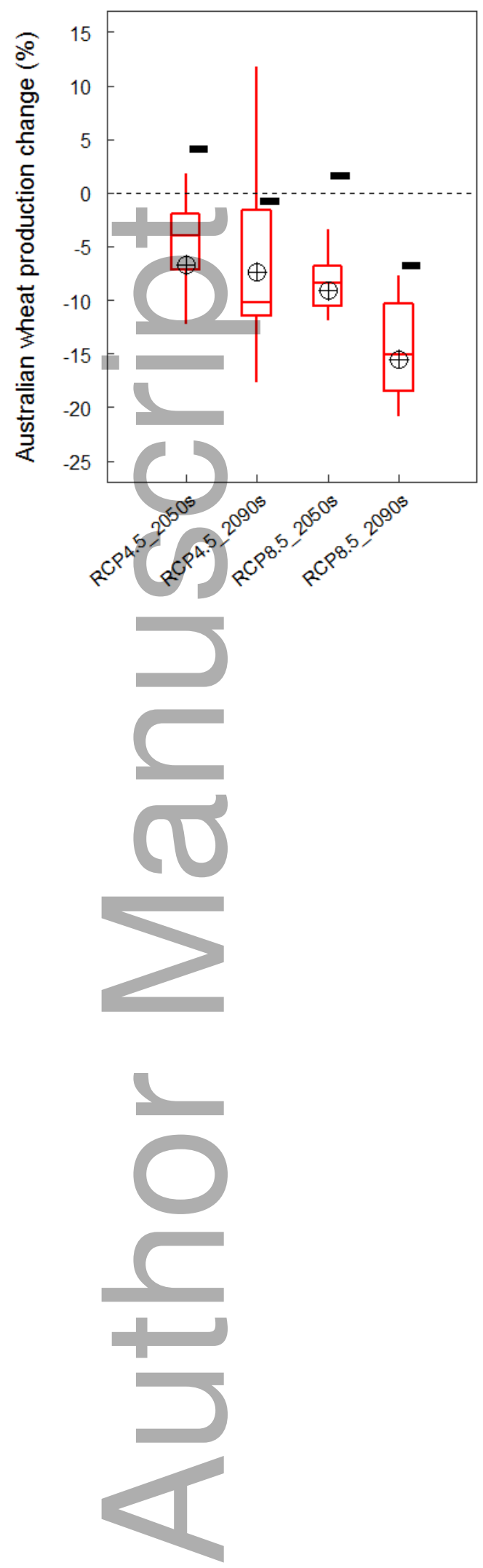

This article is protected by copyright. All rights reserved 


\section{University Library}

\section{- M M N E R VA A gateway to Melbourne's research publications}

Minerva Access is the Institutional Repository of The University of Melbourne

Author/s:

Wang, B;Liu, DL;O'Leary, GJ;Asseng, S;Macadam, I;Lines-Kelly, R;Yang, X;Clark, A;Crean, J;Sides, T;Xing, H;Mi, C;Yu, Q

Title:

Australian wheat production expected to decrease by the late 21st century.

Date:

2018-06

Citation:

Wang, B., Liu, D. L., O'Leary, G. J., Asseng, S., Macadam, I., Lines-Kelly, R., Yang, X., Clark, A., Crean, J., Sides, T., Xing, H., Mi, C. \& Yu, Q. (2018). Australian wheat production expected to decrease by the late 21st century.. Glob Chang Biol, 24 (6), pp.2403-2415. https://doi.org/10.1111/gcb.14034.

Persistent Link:

http://hdl.handle.net/11343/261121 